\title{
Systemic Thrombolytic Therapy Alone and in Combination with Mechanical Revascularization in Acute Ischemic Stroke in Two Children
}

\author{
B. Modrau $\quad$ L. Sørensen ${ }^{b} \quad$ N.J. Bartholdy ${ }^{b} \quad$ P. von Weitzel-Mudersbach ${ }^{a}$ \\ G. Andersen ${ }^{\mathrm{a}}$ P.V. Rasmussen ${ }^{\mathrm{a}}$ \\ Departments of a Neurology and ${ }^{b}$ Neuroradiology, Aarhus University Hospital, Aarhus, Denmark
}

\section{Key Words}

Acute stroke - Thrombolytic therapy - Endovascular technique

\section{Abstract}

Thrombolytic therapy is not recommended for acute ischemic stroke (AIS) in patients under the age of 18 and published experience is limited. In this case report, we describe two children treated with systemic thrombolytic therapy. One child received additional mechanical revascularization and achieved a good clinical outcome. The differences in the fibrinolytic system and the different etiology of AIS in childhood may limit a simple extrapolation of the adult guidelines for systemic thrombolytic therapy. Acute multimodal imaging to clarify the etiology of AIS might help to select the most appropriate treatment modality.

\section{Introduction}

Systemic thrombolytic therapy with recombinant tissue plasminogen activator (rt-PA), intra-arterial thrombolytic therapy, and mechanical revascularization are therapeutic options in acute ischemic stroke (AIS) in adults [1-3]. Published experience in AIS in childhood is limited and randomized controlled trials are not available.

\section{Case Reports}

Case 1

A previously healthy 14 -year-old boy was admitted with acute onset of severe left hemiparesis with a National Institute of Health Stroke Scale (NIHSS) score of 12. There was no prior history of trauma, infection or family history of migraine or other cerebrovascular disease, but the boy was complaining of 
frontal headache over the last 2 weeks. Brain CT was normal. Intravenous rt-PA infusion $(0.9 \mathrm{mg} / \mathrm{kg})$ was started $3 \mathrm{~h}$ after onset of symptoms but was discontinued after $2 / 3$ of dosage because of serious neurological deterioration. We immediately performed an MRI which revealed acute ischemic lesions in both territories of the anterior cerebral arteries (ACA) and the left middle cerebral artery (MCA). MR angiography (MRA) showed the right ACA without flow signal, the left internal carotid artery (ICA) with an intracranial stenosis, and several MCA branches with lack of flow (fig. 1).

Several differential diagnoses were considered: dissection, isolated cerebral vasculitis, arterial spasms, infection, multiple cardiac embolism, and intoxication. Further work-up showed normal ECG, echocardiography and chest X-ray. Routine blood samples and extended coagulation tests were normal. Screening for heroin, amphetamine, ecstasy, ethanol, and cocaine in blood and urine was negative. MRA of the precerebral carotid arteries showed no dissection or any other abnormalities. A lumbar puncture was avoided because of clinical concern of increased intracranial pressure. Follow-up MRI showed infarction of the right ACA territory. The right ACA was still without flow signal. The boy developed clinical signs of intracranial incarceration and died few days later.

\section{Case 2}

A previously healthy 10-year-old boy was admitted with acute severe left hemiparesis (NIHSS 16) and headache after jumping on a trampoline. There was no history of infection or family history of migraine or other cerebrovascular disease. Brain CT showed a hyperdense signal in the right MCA. MRI revealed an acute ischemic lesion in the right MCA territory, occlusion of the right ICA, and a thrombus in the right MCA (ig. 2). Intravenous rt-PA infusion $(0.9 \mathrm{mg} / \mathrm{kg})$ was started within $3 \mathrm{~h}$ after onset of symptoms. As no improvement was observed at the end of the rt-PA infusion, mechanical revascularization was performed. A goose neck snare was passed through the thrombus which was partially fragmented and finally dissolved. Flow was established in the right MCA and the branches $5 \frac{1}{2} \mathrm{~h}$ after the onset of stroke (fig. 2). The potential trauma (bouncing trampoline) and thrombus formation in the ICA made an intima dissection most likely, but could not be confirmed by angiography. No stent was used and platelet inhibition was started the next day. Transesophageal echocardiography and routine blood samples, including extensive coagulation tests, were all normal. There were no signs of infection.

The boy improved (NIHSS 13 the next day) and was transferred to the Department of Pediatric Neurorehabilitation on day 3 . At 3 month, he was back to school, but was still suffering a slight hemiparesis (modified Rankin scale (mRs) 2). Five months later, the boy was fully recovered without any neuropsychological deficits. Control MRI showed residuals after infarction in the right MCA territory (fig. 2).

\section{Discussion}

Thrombolytic therapy is not recommended for AIS in patients under the age of 18 . The current American Heart Association Pediatric Stroke Guidelines advocate thrombolytic therapy for childhood AIS only in the setting of clinical trials [4]. In contrast, the European Stroke Organization Guidelines suggest that intravenous rt-PA may be administered in selected patients under the age of 18 beyond the current European recommendations [5]. Experience with systemic thrombolytic therapy and intra-arterial revascularization in AIS in children is limited. The Nationwide Inpatient Sample in the US recorded data of 2,904 children with stroke [6]. Only $1.6 \%$ of children received thrombolytic therapy. In the International Pediatric Stroke Study (687 children), 2\% of children received thrombolytic therapy, $9 \%$ received intravenous and $6 \%$ intra-arterial therapy [7]. Both studies showed increased in-hospital mortality and worse outcome in children treated with thrombolytic therapy compared to conservative treatment, probably reflecting a treatment selection bias towards more severe stroke. Furthermore, the 


\begin{tabular}{c|l|l|l}
$\begin{array}{c}\text { Case Reports in } \\
\text { Neurology }\end{array}$ & $\begin{array}{l}\text { Case Rep Neurol 2011;3:91-96 } \\
\text { DOl: 10.1159/000327554 }\end{array}$ & $\begin{array}{l}\text { Published online: } \\
\text { April 12, 2011 }\end{array}$ & $\begin{array}{l}\odot \text { 2011 S. Karger AG, Basel } \\
\text { ISSN 1662-680X } \\
\text { www.karger.com/crn }\end{array}$ \\
\hline
\end{tabular}

thrombolytic therapy often deviated from the current adult stroke guidelines by delayed initiation.

In contrast, a review of 17 cases published in the literature, which were treated with systemic thrombolytic therapy or intra-arterial revascularization, [8] probably reflects a publication bias towards positive results with good outcome and low mortality. Sixteen children survived and 12 had a good clinical outcome (mRs 0-1).

Our two children were treated according to the stroke treatment guidelines for adults, and no rt-PA related intracranial hemorrhage or other side effects were seen.

Recanalization could not be achieved by systemic thrombolytic therapy alone in our two cases. Lower concentration of tissue plasminogen activator and higher concentration of plasminogen activator inhibitor type 1 in children [9] might influence the dose-response relation of rt-PA.

Systemic thrombolytic therapy is approved in AIS in adults, in whom atherothrombosis is the most frequent cause of ischemic stroke. In contrast, in children, cardiac disease, prothrombotic or hematologic disorders, dissection, moyamoya disease and vasculitis are common etiologies [10]. However, our children were both previously healthy. In the first case, endovascular therapy was not available in our center at that time. The child died of brain incarceration due to progressing ischemic edema. The history of headache over the last 2 weeks was suspicious for vasculitis, but now signs of inflammation were found and the later organ transplantations caused no systemic vasculitis. There were no other medical conditions that might have indicated that the changes on MRA were associated with the moyamoya syndrome. Another consideration was arterial spasm due to intoxication, but the screening for toxins was negative. Autopsy was not permitted by the parents, and the stroke etiology remained unclear. In the second case, the history of a potential trauma and thrombus formation in the distal ICA made an intima dissection most likely, but could not be confirmed on angiography or MRI after successful mechanical revascularization. The clinical outcome after 3 month was good (mRs 2) and full recovery was seen after 5 month.

In conclusion, treatment of AIS in childhood without being part of a randomized controlled trial needs a careful individual approach. Differences in the fibrinolytic system and the different etiology of AIS in childhood may limit a simple extrapolation of the adult guidelines for systemic thrombolytic therapy. Acute multimodal imaging with MRA, CT angiography, or angiography to clarify the etiology of AIS might help to select the most appropriate treatment modality.

\section{Disclosure Statement}

The authors have nothing to disclose. 


\begin{tabular}{c|l|l|l}
$\begin{array}{c}\text { Case Reports in } \\
\text { Neurology }\end{array}$ & $\begin{array}{l}\text { Case Rep Neurol 2011;3:91-96 } \\
\text { DOl: 10.1159/000327554 }\end{array}$ & $\begin{array}{l}\text { Published online: } \\
\text { April 12, 2011 }\end{array}$ & $\begin{array}{l}\text { O 2011 S. Karger AG, Basel } \\
\text { ISSN 1662-680X } \\
\text { www.karger.com/crn }\end{array}$ \\
\hline
\end{tabular}

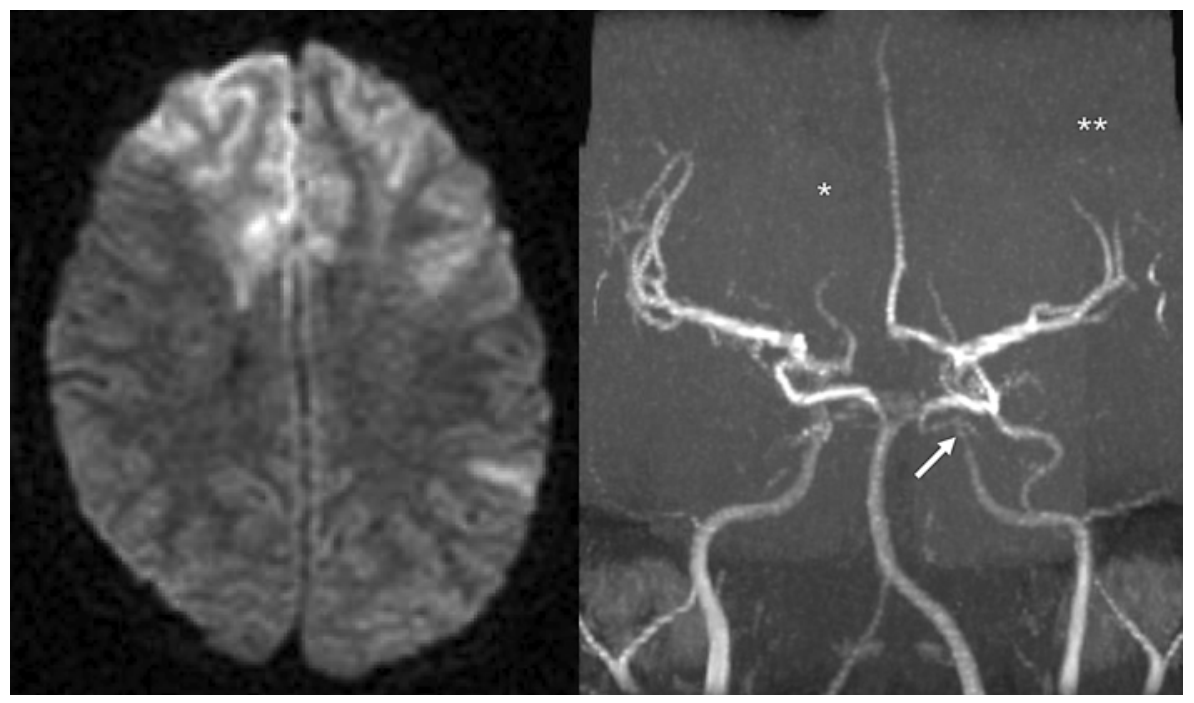

Fig. 1. MRI immediately after interruption of the thrombolytic therapy: acute ischemic lesions of the ACA territory bilateral, and the left MCA. ${ }^{*}$ Lack of flow in the right ACA; ${ }^{* *}$ lack of flow signal in several branches of the left MCA; $\uparrow$ intracranial stenosis of the left internal carotid artery. 


\begin{tabular}{c|l|l|l}
$\begin{array}{c}\text { Case Reports in } \\
\text { Neurology }\end{array}$ & $\begin{array}{l}\text { Case Rep Neurol 2011;3:91-96 } \\
\text { DOI: 10.1159/000327554 }\end{array}$ & $\begin{array}{l}\text { Published online: } \\
\text { April 12, 2011 }\end{array}$ & $\begin{array}{l}\text { @ 2011 S. Karger AG, Basel } \\
\text { ISSN 1662-680X } \\
\text { www.karger.com/crn }\end{array}$ \\
\hline
\end{tabular}
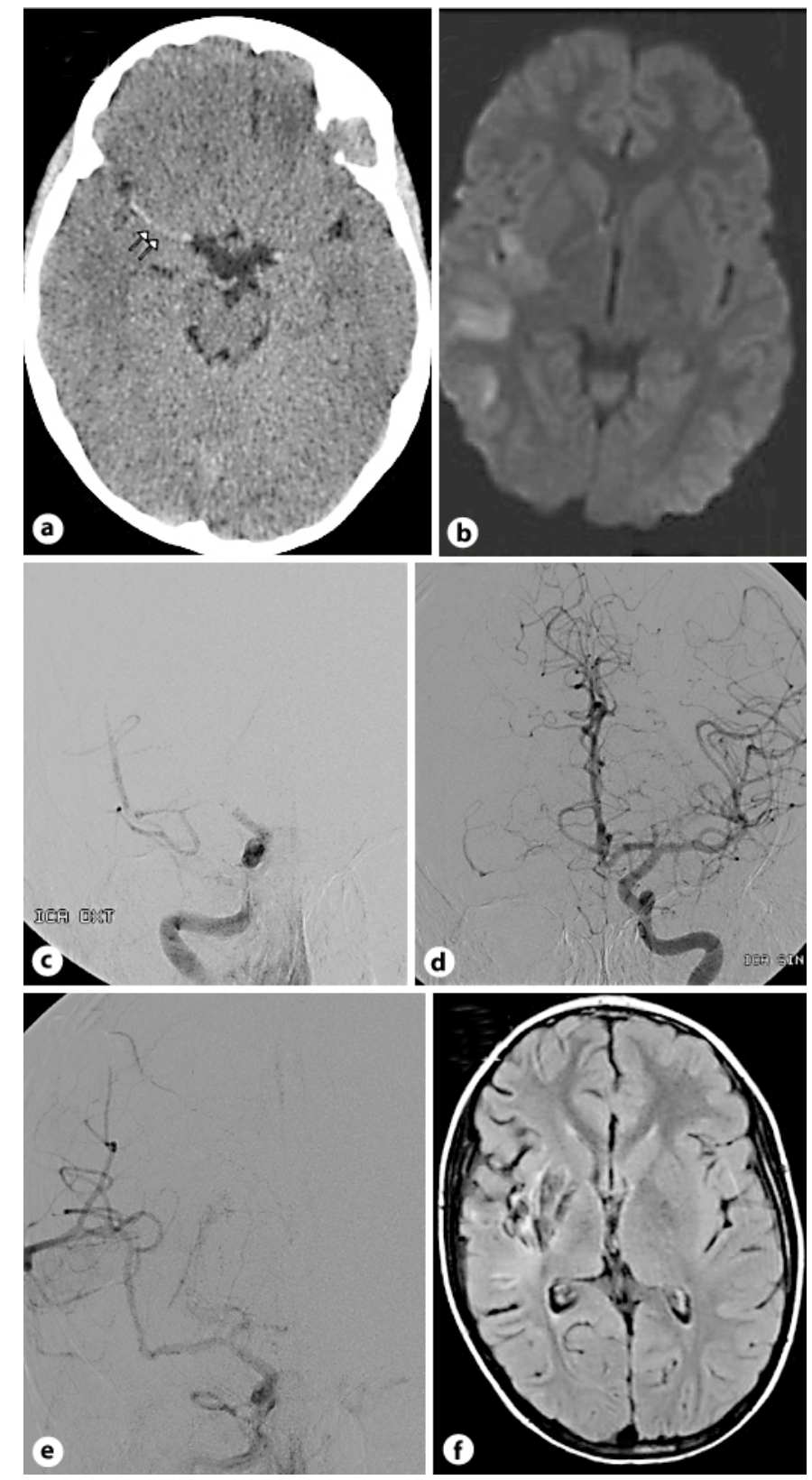

Fig. 2. a Brain CT with hyperdense right MCA. b MRI with acute ischemic lesion in the right MCA territory. c Angiography with occlusion of the right ICA at the skull base, occlusion of the right ACA and partial occlusion of the right MCA. d Angiography with normal left ICA, ACA and MCA. e Angiography after mechanical revascularization with reestablished flow in the right MCA and branches. $f$ MRI control at 5 months with residual infarction in the right MCA territory. 


\section{References}

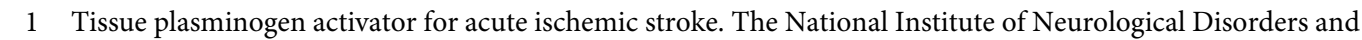
Stroke rt-PA Stroke Study Group. N Engl J Med 1995;333:1581-1587.

- Hacke W, Kaste M, Bluhmki E, Brozman M, Davalos A, Guidetti D, et al: Thrombolysis with alteplase 3 to 4.5 hours after acute ischemic stroke. N Engl J Med 2008;359:1317-1329.

-3 Smith WS, Sung G, Starkman S, Saver JL, Kidwell CS, Gobin YP, Lutsep HL, Nesbit GM, Grobelny T, Rymer MM, Silverman IE, Higashida RT, Budzik RF, Marks MP: Safety and efficacy of mechanical embolectomy in acute ischemic stroke: results of the MERCI trial. Stroke 2005;36:1432-1438.

-4 Roach ES, Golomb MR, Adams R, et al: Management of stroke in infants and children: a scientific statement from a Special Writing Group of the American Heart Association Stroke Council and the Council on Cardiovascular Disease in the Young. Stroke 2008;39:2644-2691.

5 European Stroke Organisation (ESO) Executive Committee; ESO Writing Committee: Guidelines for management of ischaemic stroke and transient ischaemic attack 2008. Cerebrovasc Dis 2008;25:457-507.

6 Amlie-Lefond C, deVeber G, Chan AK, et al: Use of alteplase in childhood arterial ischemic stroke: a multicentre, observational, cohort study. Lancet Neurol 2009;8:530-536.

7 Janjua N, Nasar A, Lynch JK, Qureshi AI: Thrombolysis for ischemic stroke in children: data from the nationwide inpatient sample. Stroke 2007;38:1850-1854.

8 Arnold M, Steinlin M, Baumann A, et al: Thrombolysis in childhood stroke. Report of 2 cases and review of the literature. Stroke 2009;40:801-807.

$\checkmark 9$ Siegbahn A, Ruusuvaara L: Age dependence of blood fibrinolytic components and the effects of low-dose oral contraceptives on coagulation and fibrinolysis in teenagers. Thromb Haemost 1988;60:361-364.

10 Sofronas M, Ichord RN, Fullerton HJ, Lynch JK, Massicotte MP, Willan AR, deVeber G: Pediatric stroke initiatives and preliminary studies: What is known and what is needed? Pediatr Neurol 2006;34:439-445. 